\title{
Wedge Splitting Test and Inverse Analysis on Fracture Behaviour of Fiber Reinforced and Regular High Performance Concretes
}

\author{
Kamil Hodicky, Thomas Hulin, Jacob W. Schmidt and Henrik Stang \\ Department of Civil Engineering, Technical University of Denmark, Kongens Lyngby DK-2800, Denmark
}

\begin{abstract}
The fracture behaviour of three fiber reinforced and regular HPC (high performance concretes) is presented in this paper. Two mixes are based on optimization of HPC whereas the third mix was a commercial mix developed by CONTEC ApS (Denmark). The wedge splitting test setup with 48 cubical specimens was used experimentally and the cracked non-linear hinge model based on the fictitious crack model was applied for the interpretation of the results. The stress-crack opening relationships were extracted by using inverse analysis algorithm for various multi-linear softening curves. This showed that the refinement of the softening curves reflects in improved accuracy of the WST (wedge splitting test) simulation in comparison with bi-linear softening curves with acceptable increase of computational time. Furthermore, the fracture mechanics parameters such as COD (crack opening displacement), fracture energy and characteristic length were experimentally determined. Experiments were performed at 1, 3, 7 and 28 days. Fracture energy, $G_{f}$, was found to increase with age, while the characteristic length, $L_{c h}$, was found to decrease.
\end{abstract}

Key words: High performance concrete, wedge splitting test, inverse analysis, fictitious crack model.

\section{Introduction}

Development of fiber reinforced concrete plays an important role in industrialization of the building industry. The possibility of replacement of ordinary reinforcement is presently a very important topic [1]. The number of practical applications of fiber-reinforced HPC (high performance concrete) is increasing in foundation slabs, foundations and walls. The fibres are likely to replace the ordinary reinforcement completely [2]. While the other structures like beams and slab, fibers can be used in combination with ordinary reinforcement or pre-stressed reinforcement. Both cases show improvement of working environment at the construction site and potential benefits due to economic factors. The one of main benefits of fiber reinforcement is an ability to transfer stress across a

Corresponding author: Kamil Hodicky, M.Sc., Ph.D. student, research field: civil engineering. E-mail: kamh@byg.dtu.dk. crack. However, if fiber-reinforced HPC is to be a more widely used material, general simple test method is needed for the concrete industry. This is necessary for fiber-reinforced HPC, where industry lacks such a method to verify their daily production quality control. Further, it would provide relevant material data to the structural engineers in order to design the structure in more cost-efficient way. As design tools seem to become more advanced and the design requirements are more complex, the need of fracture properties is required for structural analysis. Therefore, a simple test method is necessary that can provide the fracture properties of fiber-reinforced HPC with acceptable accuracy, which can be used by companies in their daily production without expensive investment to testing equipment.

In last two decades, the tensile behaviour of non-fiber and fiber reinforced concretes is mostly described by the concept of the fictitious crack model. The most often used non-linear fictitious crack model was originally developed by Hillerborg [3]. This model 
is able to closely describe the fracture properties of concrete. However, determination of softening curves of stress-crack opening relationships can cause particular difficulties like in case of uniaxial tensile test and three point bending tests [4]. Another option is the WST (wedge splitting test) setup, which is made for indirect determination of the softening curve. The WST was originally proposed by Linsbauer and Tschegg [5] and later developed by Brühwiler and Wittmann [6]. The researchers have greatly used the WST-method, and recently interest in the method increased rapidly. Its main advantage lies in its simplicity and stability. Furthermore, a standard cube is used, but the test can also be performed on core-drilled samples from the existing structure. Moreover, it was proven by Østergaard et al. [4] and Hansen et al. [7] that the test is suitable for early-aged concretes because it does not suffer problems caused by self-weight of the specimen. The work of Elser et al. [8] should be mentioned as well. Their work presented the fracture behaviour of polypropylene fiber-reinforced concrete.

The present paper focuses on the inverse analysis of WST approach developed by Østergaard et al. [4,9] for bi-linear softening curve and the approach, which comes out Skocek et al. [10] work for multi-linear softening curve. So far, Østergaard's bi-linear softening curves are mostly used to approximate the softening behaviour of concretes. It is expected that refinement of the softening curves will reflect in improved accuracy of the WST simulation. For that purpose, the semi-analytical approached is used as the background for inverse analysis of the WST. The inverse analysis is capable in estimating both elastic and fracture properties from the WST. Fracture energy, $G_{f}$, was found to increase with age, while the characteristic length, $L_{c h}$, was found to decrease.

\section{Modeling}

Loading of the specimen by wedge leads to splitting force and subsequently initiation of a crack at the bottom of the notch. Furthermore, with increase of load stable crack propagation is observed. The control of the experiment may be performed by crack mouth opening displacement or by constant displacement rate of the wedge. The CHM (crack hinge model) to the WST geometry was developed by Ulfkjaer et al. [11] and later extended by Olesen [12]. The CHM simulates the area closely surrounded by propagated crack. The hinge is modeled as array of springs, which are attached to the rigid boundaries of the element. The stress transferred by the spring is assumed to be linear elastic in the pre-cracked state, whereas the cracked state is determined by the stress-crack opening relationship as shown in Eq. (1):

$$
\sigma= \begin{cases}\sigma(\varepsilon)=E \varepsilon & \text { Preckracked State } \\ \sigma_{w}(w)=g(w) f_{t} & \text { Cracked State }\end{cases}
$$

where, $E$ represents elastic modulus, $\varepsilon$ denotes elastic strain, $\sigma_{w}(w)$ denotes stress-crack opening relationship with crack opening $w$, and $f_{t}$ represents tensile strength. In Fig. 1, the function $g(w)$ is for the $N$-linear $(N \geq 2)$ softening curve is shown and is defined as :

$$
g(w)=b_{i}-a_{i} w ; \quad w_{(i-1)}<w<w_{i}
$$

where, $w_{i}$ corresponds to the intersection of $i$-th and $i+$ 1 th line and has the form:

$$
w_{i}=\frac{b_{i}-b_{i+1}}{a_{i}-a_{i+1}} ; i<N
$$

The critical crack width (width at which $g(w)=0$ ) is calculated by:

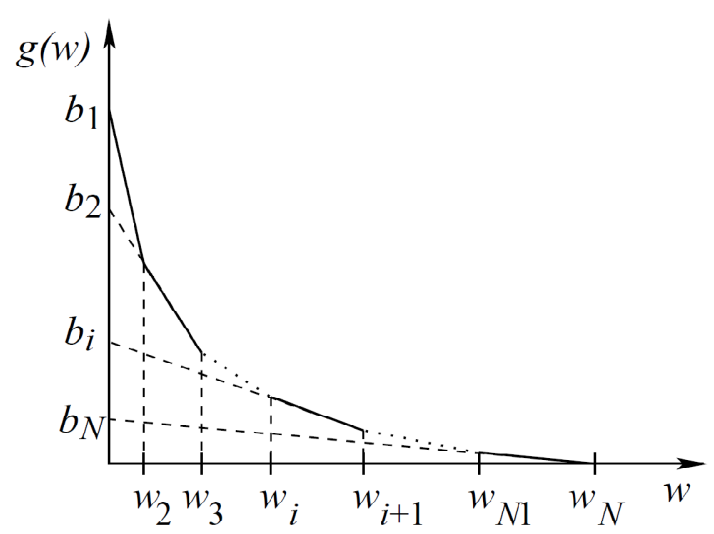

Fig. 1 The scheme of multi-linear softening curve. 


$$
w_{N}=w_{c}=\frac{b_{N}}{a_{N}}
$$

With $N$ equals to number of lines in the softening curve. Fig. 2 shows hinge model geometry, which is described by the half of the angular deformation $\varphi$ and depth of the neutral axis $y_{0}$.

Olesen [12] analytically determined crack opening $w(y)$ for each point $y$ for known stress $\sigma(y)$. The mean of longitudinal strains, $\varepsilon^{*}(y)$ is then calculated as:

$$
\varepsilon^{*}(y)=\left(y-y_{0}\right) 2 \varphi / s
$$

Then deformation of an incremental strip of the hinge is given by $u(y)=s \varepsilon^{*}(y)$, where, $s$ is the length of the hinge $(s=0.5 h)$. Once crack occurs, $u(y)$ can be computed as the sum of the elastic deformation and the crack opening according to Eq. (6).

$$
u(y)=s \varepsilon^{*}(y)=s \frac{\sigma_{w}(w(y))}{E}+w(y)
$$

The stress distribution equation can be obtained by combining Eqs. (5) and (6) as follows:

$$
\sigma_{w}(w(y))=\frac{\varsigma_{i}-2 \varphi\left(y-y_{0}\right) \beta_{i}}{1-\beta_{i}} \frac{E}{s}
$$

Solving Eq. (7) by introducing cohesive law (Eq. (1)) with respect to $w(y)$ and $\sigma_{w}(w(y))$ the following solution is observed:
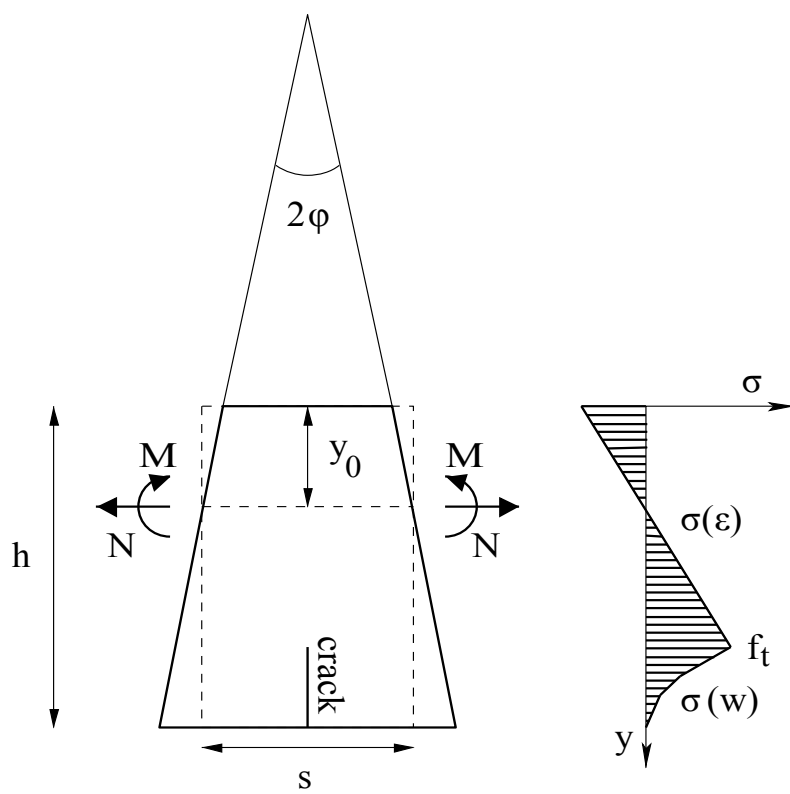

Fig. 2 The hinge model and assumed stress distribution.

$$
\begin{gathered}
\sigma_{w}(w(y))=\frac{\varsigma_{i}-2 \varphi\left(y-y_{0}\right) \beta_{i}}{1-\beta_{i}} \frac{E}{s} \\
w(y)=\frac{2 \varphi\left(y-y_{0}\right)-\varsigma_{i}}{1-\beta_{i}}
\end{gathered}
$$

where, $\varsigma_{i}$ and $\beta_{i}$ are dimensionless factors:

$$
\beta_{i}=\frac{f_{t} a_{i} S}{E} ; \varsigma_{i}=\frac{f_{t} b_{i} S}{E}
$$

Additional information on the development and implementation of the $\mathrm{CHM}$ can be found in references $[4,9,11]$. However, two equations have to be fulfilled to determine the material properties from the CHM:

$$
M_{\text {ext }}-M_{\text {hinge }}=0 ; C M O D_{\text {obs }}-C M O D_{W S T}=0
$$

where, $M_{\text {ext }}$ is the external bending moment and $M_{\text {hinge }}$ denotes bending moment transferred by hinge. The $C M O D_{\text {obs }}$ represents the observed $C M O D$ and $C M O D_{W S T}$ is computed $C M O D$ from the hinge. The external bending moment, $M_{\text {ext }}$ can be calculated as follow:

$$
M_{e x t}=P_{s p}\left(d_{2}-y_{0}\right)+\frac{1}{2} P_{v} d_{1}+\frac{1}{2} m g e
$$

where,

$$
P_{v}=P_{s p} \frac{2 \tan \alpha_{w}+\mu_{c}}{1-\mu_{c} \tan \alpha_{w}}
$$

refers to splitting load, $P_{s p}$, and vertical load $P_{v} ; \alpha_{w}$ stands for wedge angle, $\mu_{c}$ for friction in the roller bearing, $m$ denotes mass of the specimen, $g$ is the acceleration of gravity and $e$ represents the horizontal distance between the axis of symmetry of the specimen and the centre of gravity of one half of the specimen. The bending moment transferred by hinge, $M_{\text {hinge }}$ is computed by:

$$
M_{\text {hinge }}=\int_{0}^{h} \sigma(y)\left(y-y_{0}\right) d y
$$

where, $\sigma(y)$ stands for for $\sigma(\varepsilon)$ or $\sigma_{w}(w)$ from Eq. (1). The $C M O D_{W S T}$ is defined as sum of elastic deformation of the specimen, $\delta_{e}$; deformation due to presence of the crack opening, $\delta_{w}$; and deformation caused by geometrical amplification, $\delta_{g}$.

$$
C M O D_{W S T}=\delta_{e}+\delta_{w}+\delta_{g}
$$


The evaluation of the elastic deformation, $\delta_{e}$ can be found in Tada et al. [13] as:

$$
\delta_{e}=\frac{P_{s p}}{E t} v_{2}
$$

where, $t$ is specimen thickness and $v_{2}$ is a function of the ratio between the length of the initial notch and the distance from the loading line to the bottom of the specimen.

$$
v_{2}=\frac{x}{(1-x)^{2}}\left(38.2-55.4 x+33.0 x^{2}\right)
$$

The ratio is given by $x=1-h / b$ (Fig. 3). The deformation due to presence of the crack opening, $\delta_{w}$ can be directly computed from Eq. (9) at $y=h$. Finally, deformation caused by geometrical amplification, $\delta_{g}$ is derived as:

$$
\delta_{g}=2(b-h)\left(\frac{\delta_{w}}{2 d}-\frac{\varphi^{e l}}{1-\beta_{i}}\right)
$$

where, $\varphi^{e l}$ is denoted as maximum elastic angular deformation of the hinge and $\beta_{i}$ is dimensionless factors defined in Eq. (10).

The computation of inverse analysis is based on three steps that are repeated until convergence criteria are obtained. The first step involves computation of elastic modulus, E. Therefore, only data corresponding to the elastic loading are considered. Determination

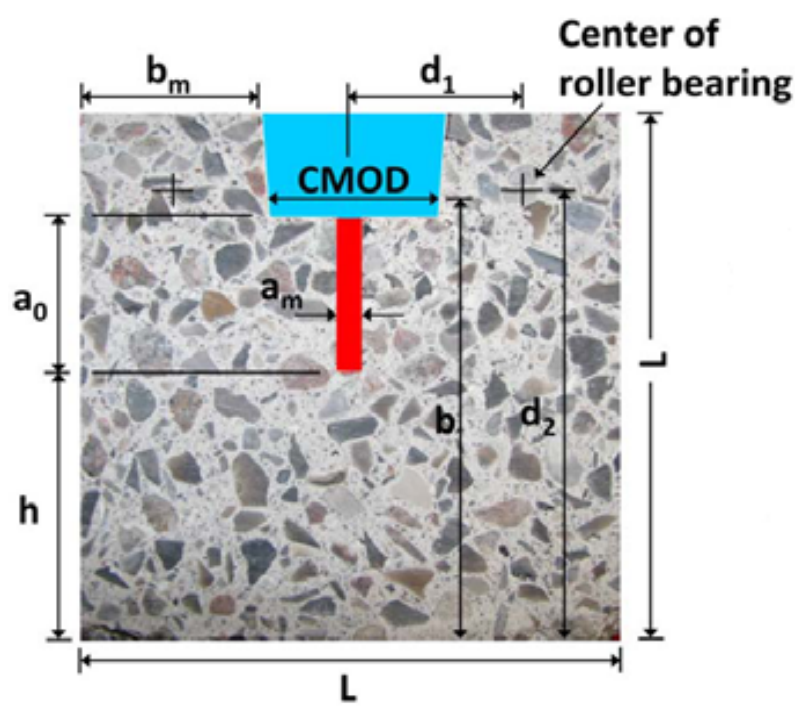

Fig. 3 WST specimen geometry with the blue area indicating the groove and the red area indicating $4.5 \mathrm{~mm}$ notch. of elastic modulus is very fast and reliable since the part of working diagram is governed by E. Once elastic modulus is found, the tensile strength $f_{\mathrm{t}}$ and the first decreasing branch of softening curve $a_{1}$ are searched. Furthermore, $N$-1 searchings are performed in order to find $a_{i}$ and $b_{i}$, where $i \geq 2$. The process of inverse analysis can be written as:

while (convergence is not achived)

$$
\begin{aligned}
& \min _{E} \sum_{j=1}^{K^{e l}}\left\|P_{j, o b s}-P_{j, \text { hinge }}\right\| \\
& \min _{f_{t}, a_{1}} \sum_{j=1}^{K}\left\|P_{j, o b s}-P_{j, \text { hinge }}\right\|
\end{aligned}
$$

for $\mathrm{i} \geq 2$

$$
\begin{aligned}
& \min _{a_{1}, b_{1}} \sum_{j=1}^{K}\left\|P_{j, o b s}-P_{j, \text { hinge }}\right\| \\
& \text { check convergence }
\end{aligned}
$$

where, $K$ is a total number of recorded load-crack opening pairs in the experiment, $K^{e l}$ is number of recorded load-crack opening pairs corresponding to elastic part of loading, $P_{j, o b s}$ denotes splitting force in $j$-th recorded load-crack opening pair, $P_{j, \text { hinge }}$ is optimized splitting force in $j$-th computed load-crack opening pair.

The each measurement can be influenced by errors, and it is impossible to fit the model exactly to the measurements, which means that the choice of the suitable robust form $\left\|P_{\text {oøs }} P_{\text {hinge }}\right\|$ plays important role. The iterative process minimizes the difference between observed loads applied in the experiments, $P_{o b s}$, and the load predicted by CHM, $P_{\text {hinge }}$ according to the error normalization function as:

$$
\left\|P_{o b s}-P_{\text {hinge }}\right\|=\sqrt{1+\frac{\left(P_{\text {obs }}-P_{\text {hinge }}\right)^{2}}{2}}-1
$$

The maximum relative difference for two subsequent sets between fracture energy; $G_{f}$ obtained from Eq. (21) and the characteristic length, $L_{c h}$ from Eq. (22) were used as stopping criteria.

$$
G_{f}=\frac{f_{t}}{2} \sum_{i=1}^{N}\left[\left(2 b_{i}-a_{i}\left(w_{i-1}+w_{i}\right)\right)\left(w_{i}-w_{i-1}\right)\right]
$$




$$
L_{c h}=\frac{E G_{f}}{f_{t}^{2}}
$$

The points obtained from the experimental load-CMOD data used by the inverse analysis program to determine the cohesive laws were selected equidistantly in regards to arch length in the normalized coordinate system. The linear interpolation is used for points selected between measured data. The arc length increment used for given analysis was 0.05 .

\section{Experimental Procedure}

The present work represents three fiber reinforced and regular HPC mixes. The first mix was a commercial mix developed by CONTEC ApS and was denoted as Contec mix. Another two HPC mix designs were based on research work of Ozbay et al. [14]. These two mixes were denoted as DTU mixes. The DTUI mix was designed to correspond to the mechanical properties of the Contec mix. The DTUII mix was adjusted by bauxite sand and fly ash to obtain better mechanical properties than Contec and DTUI. The mix designs are shown in Table 1. A 601 pan mixer was used for mixing, mixing time was 2 min for the dry mixing and 5 min with water and super-plasticizer. The vibrating time was chosen to be $30 \mathrm{~s}$. After casting, the specimens were left to harden in a climate chamber $(22$ $\pm 2{ }^{\circ} \mathrm{C}$ and $\left.65 \pm 5 \% \mathrm{RH}\right)$. Specimens were demoulded after $24 \mathrm{~h}$ and put in the water at $20{ }^{\circ} \mathrm{C}$ for curing. The experimental programme presented in this paper included 48 wedge splitting tests.

WST-specimens were casted in special PVC moulds with groove and notch made for this purpose. The geometry of the WST-specimen is shown in Fig. 3. The WST-cube has length $L=100 \mathrm{~mm}$ and thickness $t=$ $100 \mathrm{~mm}$. The height of the ligament was $h=50 \mathrm{~mm}$. The mean width of notch $a_{m}=4.5 \mathrm{~mm}$, however, the walls of a real notch were a little bit inclined in order to avoid demoulding problems. The length of notch was $a_{0}=28 \mathrm{~mm}$. Position of center of roller bearing, where splitting load is applied was $d_{1}=39.5 \mathrm{~mm}$ and $d_{2}=85.4$ $\mathrm{mm}$.

Fig. 4 shows WST experimental setup, where the rotational joints are used to prevent unwanted restrained. The rotational joint (a rectangular bar) was placed below specimen combined with roller bearing above the wedge.

Loading is controlled by displacement measurements from a clip gage inserted into the groove of the WST specimen to measure the CMOD. Distance $b=83.5 \mathrm{~mm}$ describes contact position of the clip gage. The clip gage was modified by using brass feet to contact the side of the groove. The vertical load was recorded by the testing machine, and subsequently used

Table 1 Mix designs $\left(\mathrm{kg} / \mathrm{m}^{3}\right)$.

\begin{tabular}{|c|c|c|c|c|c|c|}
\hline Mix & Contec & DTUI & DTUII & Contec-F & DTUIF & DTUIIF \\
\hline Cement (CEM I 52.5 R) & - & 495 & 460 & - & 495 & 460 \\
\hline Binder Contop S 105-2 & 582.3 & - & - & 582.3 & - & - \\
\hline $\mathrm{CA}$, granite, $02-05 \mathrm{~mm}$ & 832.3 & 868.4 & 1015.6 & 832.3 & 868.4 & $1,015.6$ \\
\hline FA, sea gravel, $0.1-1.5 \mathrm{~mm}$ & 763.7 & 781.6 & - & 763.7 & 781.6 & - \\
\hline FA, bauxite sand, $0-1 \mathrm{~mm}$ & - & - & 609.4 & - & - & 609.4 \\
\hline Silica fume & - & 55 & 57.5 & - & 55 & 57.5 \\
\hline Fly ash & - & - & 57.5 & - & - & 57.5 \\
\hline Superplasticizer & - & 11 & 25.9 & - & 11 & 25.9 \\
\hline Glass fibers & - & - & - & 4.04 & 4.0 & 3.5 \\
\hline Polypropylene fibers & - & - & - & 2.02 & 2.0 & 1.78 \\
\hline Total dry mass & $2,178.3$ & 2,200 & 2,200 & $2,184.4$ & 2,206 & $2,205.3$ \\
\hline Water-cementitious material ratio & 0.304 & 0.25 & 0.25 & 0.304 & 0.25 & 0.25 \\
\hline Water-cementitious material ratio ${ }^{*}$ & - & 0.27 & 0.295 & - & 0.27 & 0.295 \\
\hline
\end{tabular}

${ }^{*}$ including the water content of the superplasticizer. 

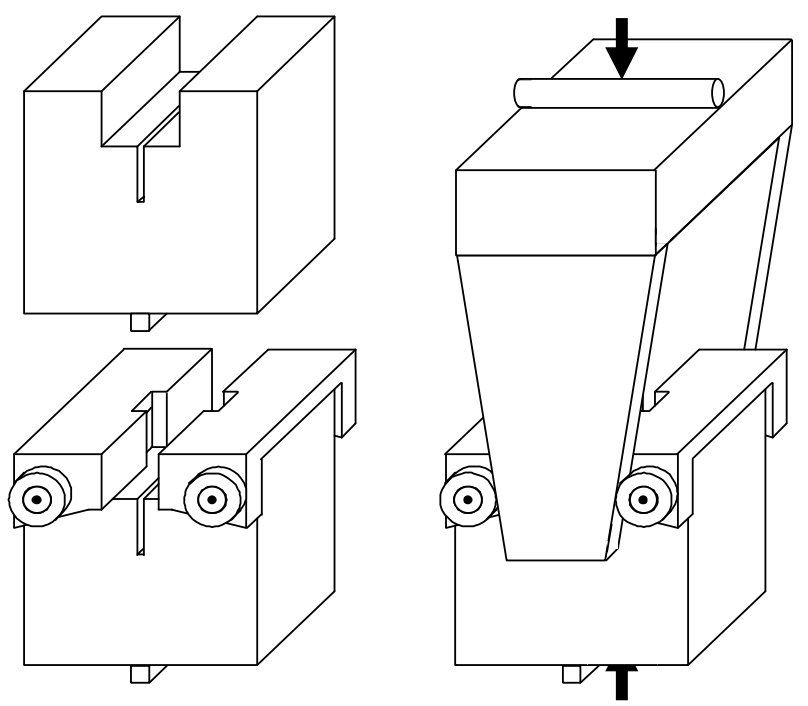

Fig. 4 Schematic showing of experimental WST test setup.

for calculation of the splitting load. The wedge angle from the vertical axis was used $15^{\circ}$. The constant displacement rate of the wedge was kept initially of $0.05 \mathrm{~mm} / \mathrm{s}$ to a CMOD of $0.5 \mathrm{~mm}$. After reaching a CMOD of $0.5 \mathrm{~mm}$, the displacement rate was increased to $0.10 \mathrm{~mm} / \mathrm{s}$ to minimize testing time.

\section{Results and Discussion}

Fig. 5a shows the load-CMOD curves demonstrate the performance of the model and of the inverse analysis (Example for DTUIF at 28 days maturity). It is visible that computation based on softening curve for $N$ $=3$ provide better approximation compared to the

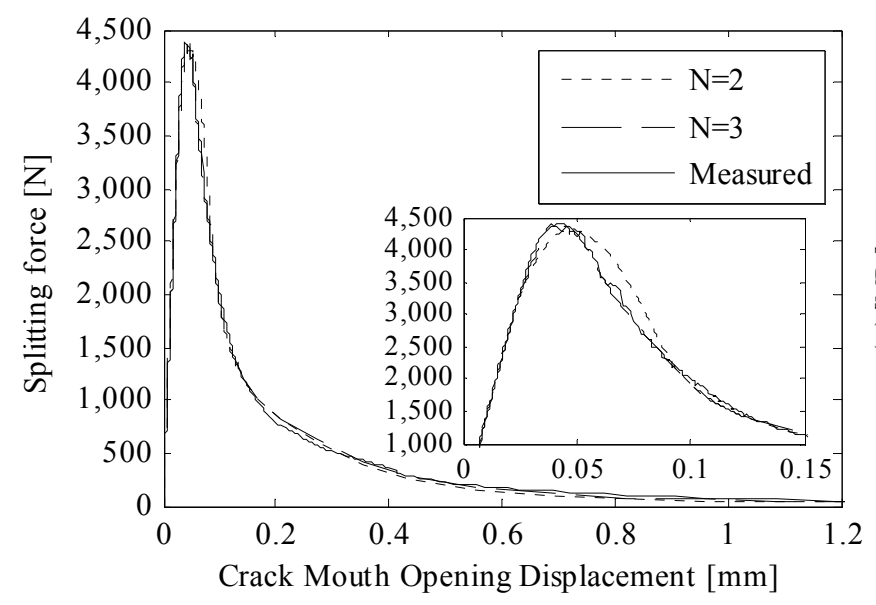

(a) bi-linear curve. The computational time was approximately $15 \mathrm{~min}$ with softening curve for $N=2$ and approximately $25 \mathrm{~min}$ with softening curve for $N=3$. The increase in computational time is compensated with increase in accuracy of the model.

Fig. $5 \mathrm{~b}$ shows an example of stress-crack opening relationships at different ages for DTUIF. Furthermore, it shows the fracture energy given by the area under the curves is increasing with age.

The development of modulus of elasticity $E$ seen in Fig. 6 shows some scatter and furthermore, a drop in $\mathrm{E}$ is seen for DTUII mix. With the exception of the Contec mixes, the mean static elastic modulus of the concretes $E_{c m}$, reached about $60 \mathrm{GPa}$ after 28 days. The static elastic modulus of the Contec mixes was at 40 $\mathrm{GPa}$, thus significantly lower. This seems to be caused by discontinues grain size distribution curve and by a disadvantageous pore size distribution of the hardened concrete. The static elastic modulus of the DTU mixes developed significantly faster than Contec mixes.

Fig. 7 shows the development in the tensile strength, $f_{t}$. The 28 days tensile strength of all HPC mixes was high around $6 \mathrm{MPa}$. The tensile strength of the DTU mixes made with silica fume, fly ash and cement with rapid hardening was observed to develop faster. After three days it was at roughly $5 \mathrm{MPa}$-well above the strength of the Contec mixes, $3 \mathrm{MPa}$. Tensile strength

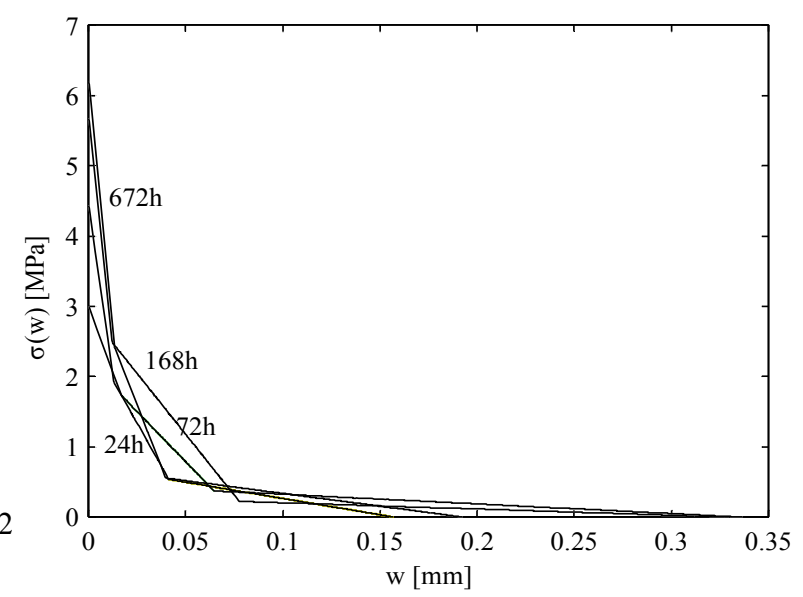

(b)

Fig. 5 Example of comparison of the measured and the computed load-CMOD curves for DTUIF at 28 day maturity (a) and stress-crack opening relationships for DTUIF for different ages (b). 
Wedge Splitting Test and Inverse Analysis on Fracture Behaviour of Fiber

Reinforced and Regular High Performance Concretes
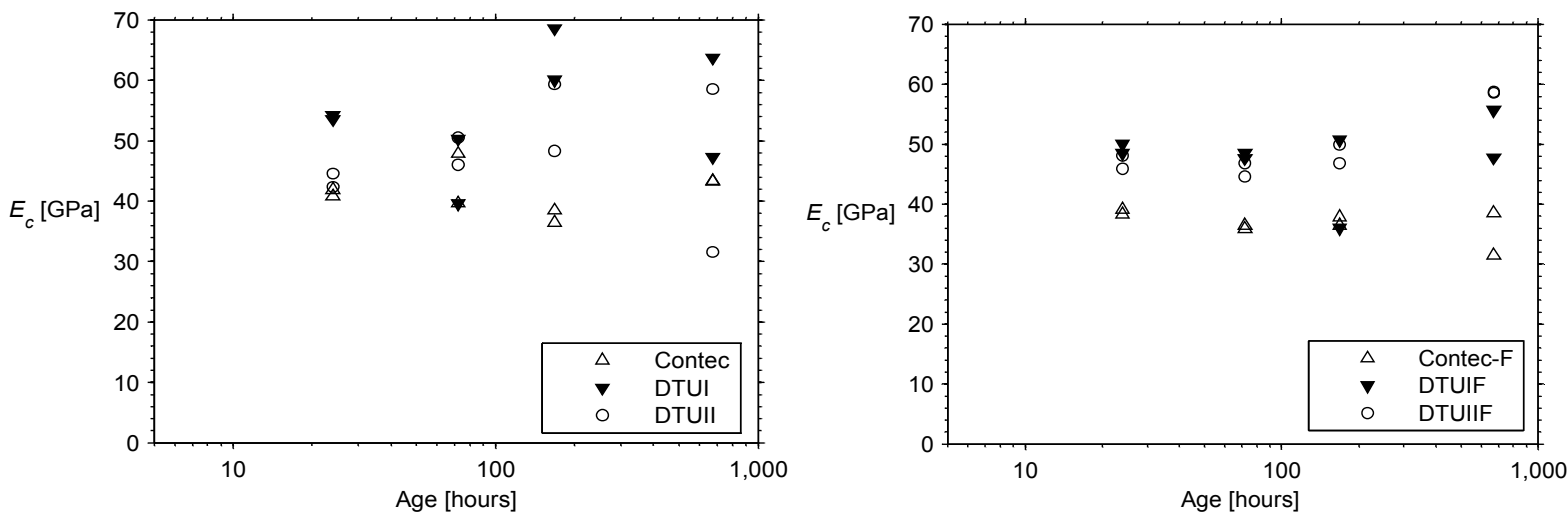

Fig. 6 Development in modulus of elasticity.
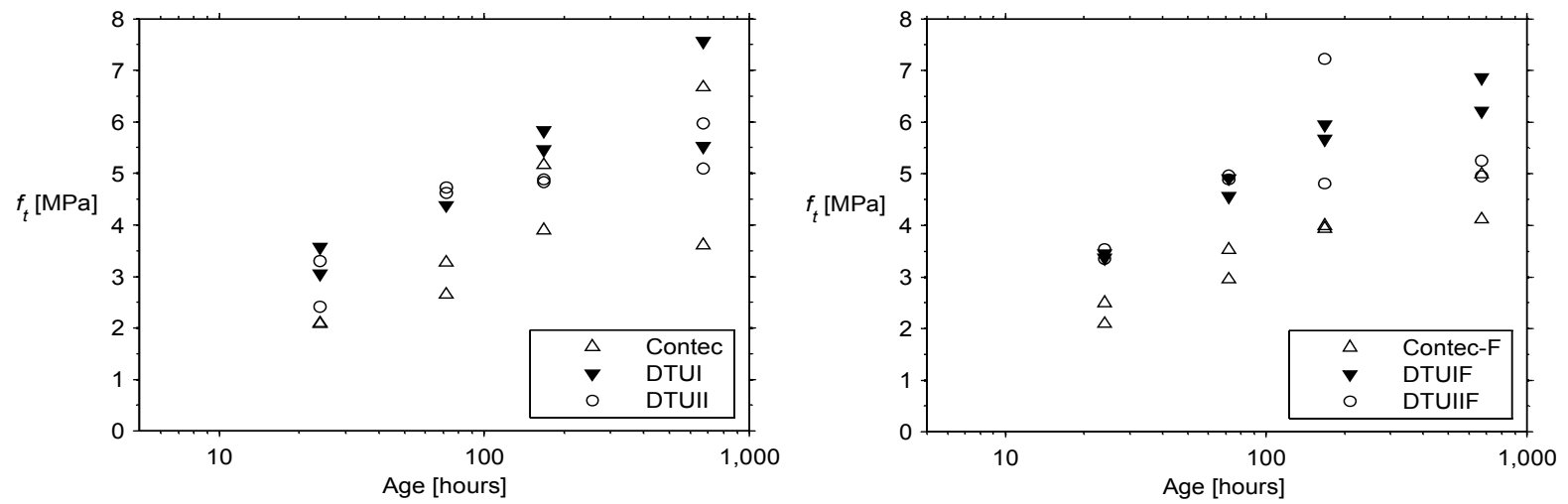

Fig. 7 Development in tensile strength.
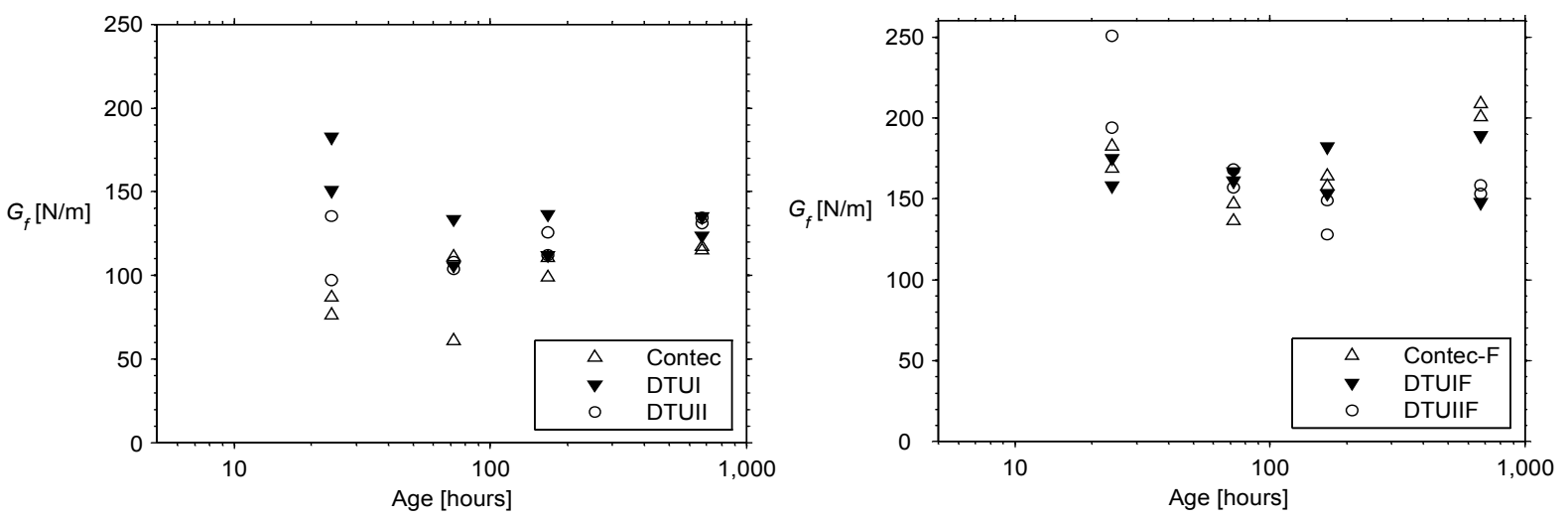

Fig. 8 Development in fracture energy.
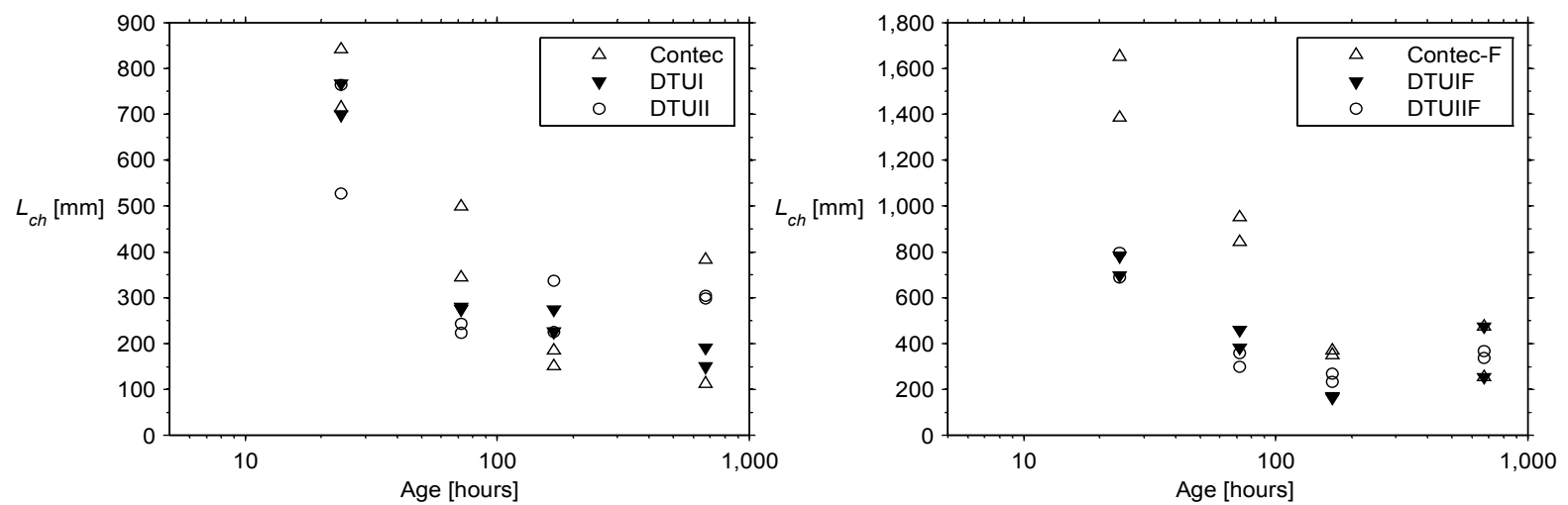

Fig. 9 Development in characteristic length. 
development of Contec mixes tended to increase slower than DTU mixes. There was no obvious change of tensile strength caused by adding fibers to HPC matrix.

In general results of development of elastic modulus $E$ and tensile strength $f_{t}$ follow the literature, e.g., the work in Ref. [4]. Their results also indicate a drop in the modulus of elasticity at 28 days.

Development in fracture energy with age is shown in Fig. 8. The development of this property is in agreement with observation found in literature, e.g., the works in Refs. [1, 4]. Same as at these papers the fracture energy is found to increase with age.

Fig. 9 shows the development in characteristic length. The general trend in the development of the characteristic length despite the scatter was observed to decrease with maturity. The same results were also found in literature, e.g., the work in Ref. [4].

\section{Conclusions}

This paper presents current knowledge of the inverse analysis of the WST. In particular, it addresses the question about the amount of information that can be retrieved from the WST using inverse analysis. The fracture behaviour of three fiber reinforced and regular HPC were investigated. The wedge splitting test setup with 48 cubical specimens was used experimentally and the cracked non-linear hinge model based on the fictitious crack model was applied for the interpretation of the results. The stress-crack opening relationships were extracted by using inverse analysis algorithm for various multi-linear softening curves. The fracture mechanics parameters such as COD (crack opening displacement), fracture energy and characteristic length were experimentally determined. Experiments were performed at 1, 3, 7 and 28 days. Fracture energy, $G_{f}$, was found to increasing with age, while the characteristic length, $L_{c h}$, was found to decrease.

The conclusions that can be drawn from this study are that:

The wedge splitting test is suitable test method for assessment of fracture properties of regular and glass-polypropylane fiber reinforced HPC.

The test method is easy to handle and the execution is relatively fast.

Using the inverse analysis, the both elastic and fracture properties may be interpreted from the test results as a bi-linear or multi-linear stress-crack opening relationship.

The refinement of the softening curves reflects in improved accuracy of the WST simulation in comparison with bi-linear softening curves with acceptable increase of computational time.

The suggested future work is to investigate the effect to varying material parameters on the fracture behavior as determined by the WST and inverse analysis, i.e., different volumes of carbon and basalt fiber reinforced polymers in HPC.

\section{Acknowledgments}

The authors greatly thank the Danish National Advanced Technology Foundation and Connovate for the financial support.

\section{References}

[1] L. Löfgren, H. Stang, J.F. Olesen, The WST-method for fracture testing of fibre-reinforced concrete, Materials and Structures 4 (2008) 197-211.

[2] A. Jansson, I. Löfgren, K. Gylltoft, Flexural behaviour of members with a combination of steel fibres and conventional reinforcement, Nordic Concrete Research 2 (42) (2010) 155-171.

[3] M. Hillerborg, M. Modeer, P.E. Peterson, Analysis of crack formation and crack growth in concrete by means of fracture mechanics and finite elements, Cement and Concrete Research 6 (1976) 773-782.

[4] L. Østergaard, D. Lange, H. Stang, Early-age stress-crack opening relationships for high performance concrete, Cement and Concrete Composites 26 (5) (2006) 563-572.

[5] H.N. Linsbauer, E.K. Tschegg, Fracture energy determination of concrete with cube shaped specimens, Zement und Beton 31 (1986) 38-40. (in German)

[6] E. Brühwiler, F.H. Wittmann, The wedge splitting test, a new method of performing stable fracture mechanics test, Engineering Fracture Mechanics 35 (1-3) (1990) 117-125.

[7] E.J. de Place Hansen, E.A. Hansen, M. Hassanzadeh, H. 
Stang, Determination of the Fracture energy of concrete: A comparison of the three-point bend test on notched Beam and the wedge-splitting test, Nordtest Project No 1327-97, SP Swedish National Testing and Research Institute, Building Technology, SP Report 09 (1998), Borås, Sweden, 1998, p. 87.

[8] M. Elser, E.K. Tschegg, S.E. Stanzl-Tschegg, Fracture behaviour of polypropylene-fibre-reinforced concrete under biaxial loading: An experimental investigation, Composites Science and Technology 56 (8) (1996) 933-945.

[9] L. Østergaard, H. Stang, J.F. Olesen, Interpretation and Inverse Analysis of the Wedge Splitting Test, Fracture Mechanics beyond 2000, EMAS Publications, Sheffield, UK, 2002, 593-600.

[10] J. Skocek, H. Stang, Inverse analysis of the wedge splitting test, Engineering Fracture Mechanics 75 (10) (2008) 3173-3188.

[11] J.P Ulfkjaer, S. Krenk, R. Brincker, Analytical model for fictitious crack propagation in concrete beams, Journal of Engineering Mechanics 121 (1) (1995) 7-15.

[12] J.F. Olesen, Fictitious crack propagation in fiber-reinforced concrete beams, Journal of Engineering Mechanics 127 (3) (2001) 272-280.

[13] H. Tada, P. Paris, G. Irwin, The stress analysis of cracks handbook, Paris Productions Incorporated, 226 Woodbourne Dr., St. Louis, Missouri, USA, 1985.

[14] E. Ozbay, M. Gesoglu, E. Guneyisi, Transport properties based multi-objective mix proportioning optimization of high performance concretes, Materials and Structures 44 (2011) 139-154. 